\title{
Deformation behavior of Austenitic stainless steel at subzero temperature
}

\author{
M.Krishnamraju1, Abhishek Kumar1, Sushil Mishra2, K Narasimhan1 \\ ${ }^{1}$ Department of Metallurgical Engineering and Material science, IIT Bombay, India. \\ 2 Department of Mechanical Engineering, IIT Bombay, India, 400076
}

\begin{abstract}
Austenitic stainless steel is one of the second generation advanced high strength steel which finds application in automobile, aerospace and cryogenic components. The component made of austenitic steel might operate in subzero temperature condition because of its excellent formability even at subzero temperature. In the present work several tensile tests were performed on austenitic stainlesssteel sheet of thickness $1.2 \mathrm{~mm}$ at $0^{\circ} \mathrm{C},-40^{\circ} \mathrm{C},-80^{\circ} \mathrm{C},-120^{\circ} \mathrm{C}$ and at different strain rates of $0.01 / \mathrm{sec}, 0.001 / \mathrm{sec}, 0.0001 / \mathrm{sec}$. The resultant mechanical properties, like yield strength, tensile strength, elongation percent and strain hardening exponent, along with phase fractions and microstructural properties were analyzed to understand the reasons for change in mechanical properties, on comparing with room temperature properties. It was noticed that tensile strength is $635 \mathrm{Mpa}$, \& strain hardening exponent is 0.38 at room temperature $\left(25^{\circ} \mathrm{C}\right)$ and tensile strength is $1236 \mathrm{Mpa}$, \& strain hardening exponent is $\mathrm{O} .49$ at $-120^{\circ} \mathrm{C}$. Similarly, $\mathrm{XRD}$ characterization revealed that strain induced martensite increased from zero percent at $25^{\circ} \mathrm{C}$ (room temperature) to 57 percent at $-120^{\circ} \mathrm{C}$ Similarly EBSD characterization revealed that grain average misorientation which also increased from room temperature to- $120^{\circ} \mathrm{C}$.
\end{abstract}

Keywords Subzero temperature, Austenitic stainless steel, strain rates, phase fractions, XRD characterization, EBSD characterization, mechanical properties.

\section{Introduction}

Stainless steels are basically alloys of Iron $(\mathrm{Fe})$, carbon $(\mathrm{C})$, and chromium $(\mathrm{Cr})$, exhibits excellent corrosion resistance property because of the strong, non-porous chromium oxide layer $(\mathrm{Cr} 2 \mathrm{O} 3)$ on the surface of the steel. Stainless steel [10] can be Ferritic, Austenitic, Martensitic, duplex and precipitation hardened type based on chromium and carbon percent. Usually ferritic stainless steels show BCC structure \& contains low carbon in the range of 0.01 to 0.12 with $10.5 \%$ to $27 \%$ chromium. Martensitic stainless steels contain carbon in the range of 0.10 to $0.15 \%$ with $12 \%$ to $14 \%$ chromium. Whereas Austenitic stainless-steel show FCC structure \& contains very low carbon in the range of 0.02 to $0.06 \%$ with $18 \%$ to $20 \%$ chromium along with $8 \%$ to $10 \%$ nickel. Nickel is added to stabilize Austenite phase in stainless steels [1, 2, 12].

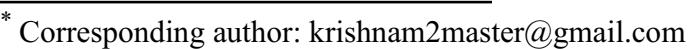

Hence Austenitic Stainless steels are corrosion resistant and ductile than others, hence having excellent formability at room temperature, even at subzero temperature because of stable of Austenite phase. Hence these steels are best preferred for cryogenic applications. However, because of low stacking fault energy aprox 17MJ/.M2, Austenite phase transforms to Martensite on deformation. This strain induced martensite [5, 8,9] increases strength and hardness of the component. The amount of martensite formed depend on amount of deformation which can be characterized by microscopic examination and XRD characterization. Similarly grain average misorientation also increases with increase of deformation which is characterized by EBSD analysis [11]. 
Swadesh et.al [4] determined tensile behaviour of $\mathrm{SS} 304$ at high temperature say $50^{\circ} \mathrm{C}$, to $650{ }^{\circ} \mathrm{C}$ at interval of $50^{\circ} \mathrm{C}, \mathrm{B}$ petit et.al [8] determined deformation behaviour of SS 304 at $-60^{\circ} \mathrm{C}$ at various stain rates and Norimitsu koga[5] studied deformation behaviour of Duplex stainless steel. But deformation behavior of SS304 at subzero temperatures say $-40^{\circ} \mathrm{C}$, $-80^{\circ} \mathrm{C}-120^{\circ} \mathrm{C}$ and at strain rates of $0.01 / \mathrm{sec} .0 .001 / \mathrm{sec}, 0.0001 / \mathrm{sec}$ is not focused much. Hence in the current study is focused much on those areas to get an insight on cryogenic behaviour of AISI304.

\section{Experimentation}

The material used for this work is Austenitic Stainless steel, AISI 304 of thickness $1.2 \mathrm{~mm}$. This material was suppled in Cold rolled \& annealed condition by the local manufacturer. As received material was tested for chemical composition, mechanical properties and microstructure.

For chemical composition, sheet sample of 50mmx 50 $\mathrm{mm}$ was cut from the sheet by using hand shear, then rough polished on 80 grid sandpaper, then chemical composition was analyzed by taking a burns on spark emitting Spectrometer Thermo Jarallesh. Chemical composition was given in table 1 similarly, for hardness value, sheet sample of $50 \mathrm{~mm} \times 50 \mathrm{~mm}$ was cut from the sheet by using hand shear, and then hardness value determined by using Rockwell hardness tester with ball indentor and ' $\mathrm{B}$ ' Scale .The hardness value is given in table 2. For mechanical properties, dog bone shaped sample cut, from the received sheet in the rolled direction by using water jet machining as per ASTM E08 as shown in figure 1, then tensile properties determined by using $250 \mathrm{KN}$ MTS axial loading system as shown in figure 2. Subzero temperature required is obtained by injecting liquid nitrogen into the chamber of testing system and necessary temperature is monitored by sensor. By using the load Vs elongation data obtained from tensile test, engineering stress, engineering strain, true stress, true strain and strain hardening exponent calculated [6,7].

Similarly samples of size $10 \mathrm{mmx} 10 \mathrm{~mm}$, collected close to fracture of tensile deformed zone, then polished mechanically using emery papers and then polished electrolytic ally by using electrolyte $(20 \%$ per chloric acid and $80 \%$ alcohol), then scans taken with a step size of 0.2 Pan analytical X-ray diffractometer ,EBSD scans taken with a step size of 0.3 on GEMINI FE-SEM. For optical microscopy, sample of size $5 \mathrm{mmx} 5 \mathrm{~mm}$ cut from the as received sheet, then rough polished on emery papers which are coated with silicon carbide of fine grade say 600,800 , 12002500 , then fine polished by using colloidal silica. Then etched with etchant 1:3 hydrochloric acid and nitric acid, then microstructure revealed at .1000X magnification on Zeiss optical Microscope as shown in figure 6

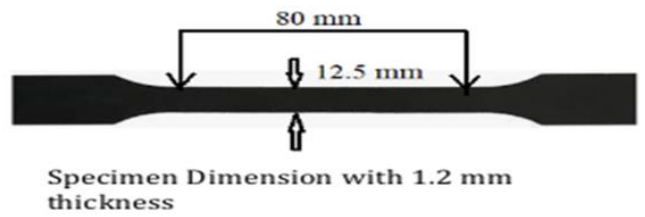

Figure: 1 standard sample for tensile test as per

ASTM E08.

\begin{tabular}{|c|c|c|c|c|c|c|c|c|c|}
\hline $\mathrm{C}$ & $\mathrm{Cr}$ & $\mathrm{Ni}$ & $\mathrm{Si}$ & & $\mathrm{P}$ & $\mathrm{S}$ & & $\mathrm{N}$ & $\mathrm{Fe}$ \\
\hline 0.029 & 18.66 & 8.066 & 0.33 & & & 0.011 & 0.12 & 0.005 & 1.301 \\
\hline
\end{tabular}

\begin{tabular}{|l|c|l|l|l|l|l|}
\hline $\begin{array}{l}\text { Hardness } \\
(\mathrm{HRB})\end{array}$ & $\begin{array}{l}\text { Yield } \\
\text { strength }\end{array}$ & $\begin{array}{l}\text { Tensile } \\
\text { Strength } \\
(\mathrm{Mpa})\end{array}$ & $\begin{array}{l}\text { Strength } \\
\text { coefficient } \\
(\mathrm{Gpa})\end{array}$ & $\begin{array}{l}\text { Elongation } \\
\text { percent } \\
(\%)\end{array}$ & $\begin{array}{l}\text { Strain } \\
\text { hardening } \\
\text { exponent( } \\
\mathrm{n})\end{array}$ & $\begin{array}{l}\text { Plastic } \\
\text { anisotropy } \\
(\mathrm{R})\end{array}$ \\
\hline 69.9 & 259.4 & 638.9 & 1.28 & 59.48 & 0.381 & 1.06 \\
\hline
\end{tabular}



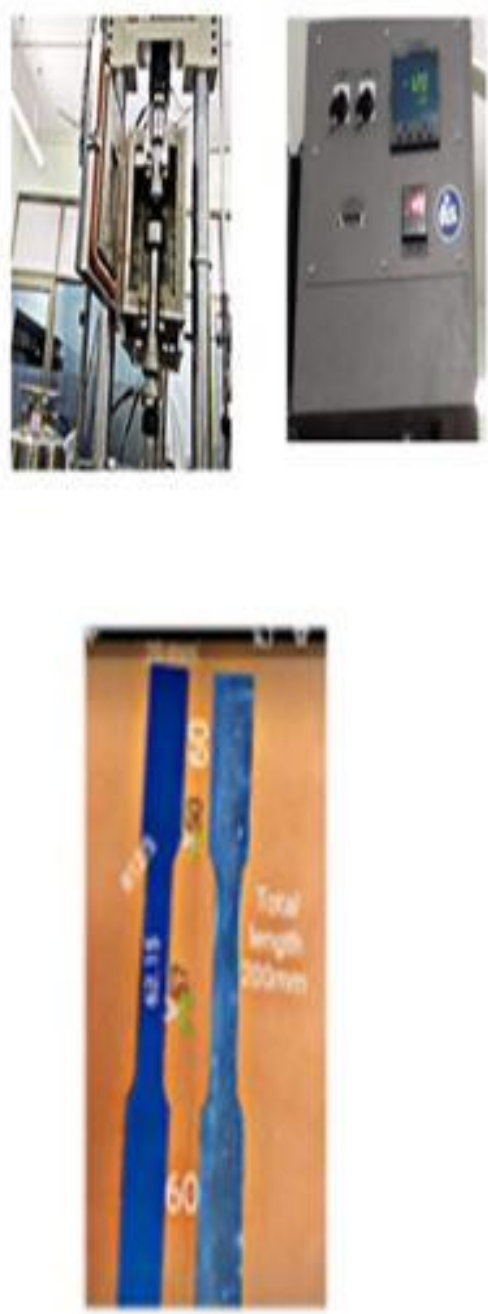

Figure 2: Tensile test set up and water jet cut samples

\section{Results and discussions}

As received material supplied by local manufacturer is subjected to spark emission Spectra analysis and composition analyzed. It showed carbon percent 0.029 , chromium percent 18.66 and nickel percent 8 . 066. Complete composition is given in table 1

Table 1 Chemical composition

As receive sheet, tested for room temperature mechanical properties like Hardness, yield strength, Tensile strength and strain hardening exponent, anisotropy etc. It was noted that yield strength is 259.4 Mpa, Tensile strength 638.9 Mpa and Strain hardening exponent is 0.381 . Complete mechanical properties given in Table. 2

Table 2 Mechanical Properties

Room temperature tensile test conducted as per ASTM E08 for two sample at a strain rate of 0.001 . Then average mechanical properties of two samples considered. Its stress strain diagrams for two sample shown in figure 3

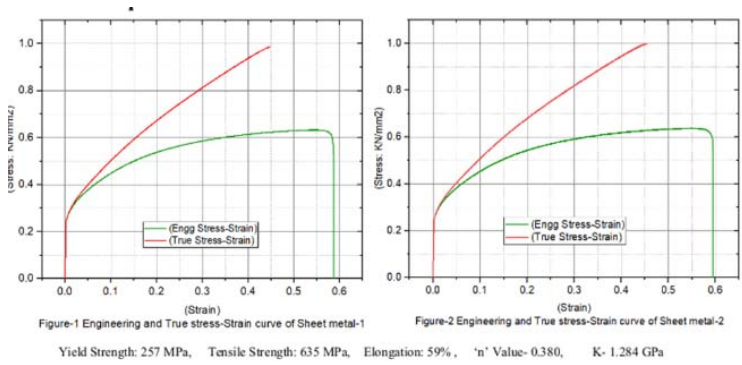

Figure 3 Stress- strain diagrams at room temperature

Subzero temperature tensile test was conducted by using $250 \mathrm{KN}$ MTS axial loading system using liquid nitrogen medium on standard tensile sample of gauge length $80 \mathrm{~mm}$ at strain rates of $0.01,0.001,0.0001$ and temperatures $\quad 0^{\circ} \mathrm{C} \quad-40^{\circ} \mathrm{C},-80^{\circ} \mathrm{C},-120^{\circ} \mathrm{C} \quad$ and engineering stress strain diagram plotted as shown in figure 4 


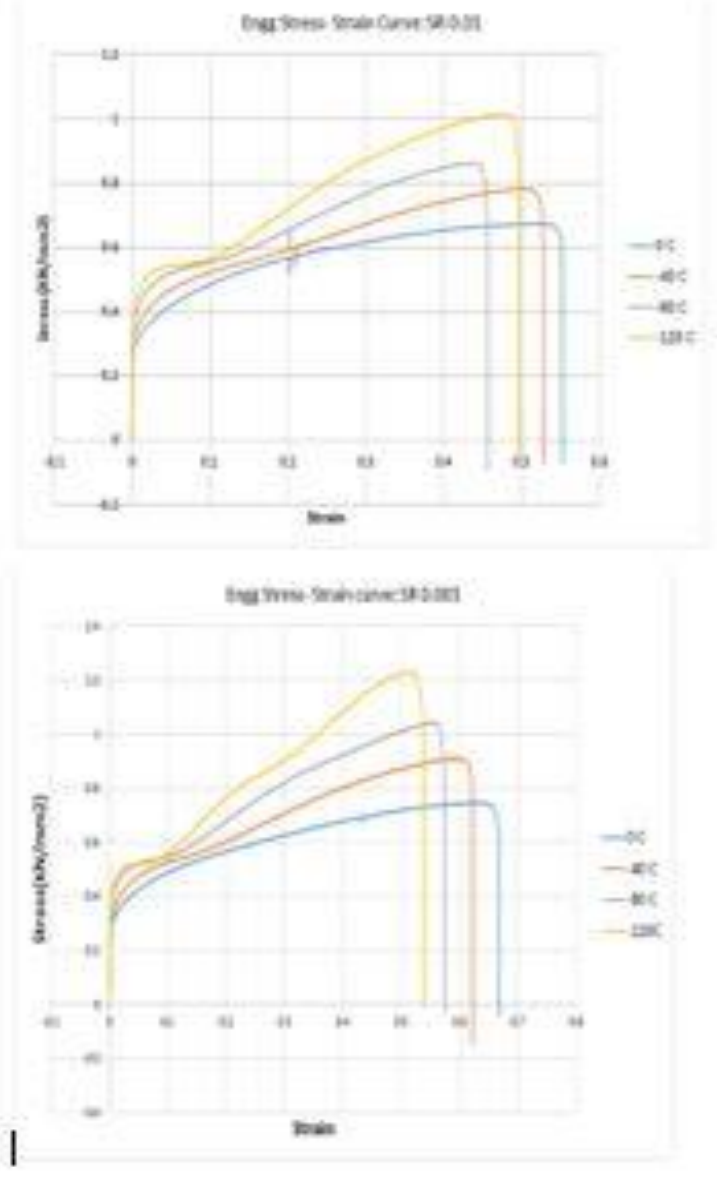

Figure 4 engineering stress strain diagram for strain rate of $0.01 \& 0.001$

Mechanical properties like yield strength, Tensile strength calculated at each temperature and strain rate and compared. It was analyzed that yield strength is $257 \mathrm{Mpa}$ at room temperate at a strain rate of $0.001 / \mathrm{sec}$ and it was $394 \mathrm{Mpa}$ at $-120{ }^{\circ} \mathrm{C}$ at a strain rate of $0.0001 / \mathrm{sec}$, and tensile strength was $635 \mathrm{Mpa}$ at room temperature at a strain rate of $0.001 / \mathrm{sec}$ and $1236 \mathrm{Mpa}$ at $-120^{\circ} \mathrm{C}$ at a strain rate of $0.0001 / \mathrm{sec}$.It was observed that both yield strength and tensile strength increased with decrease of temperature and strain rate as shown in Figure 5
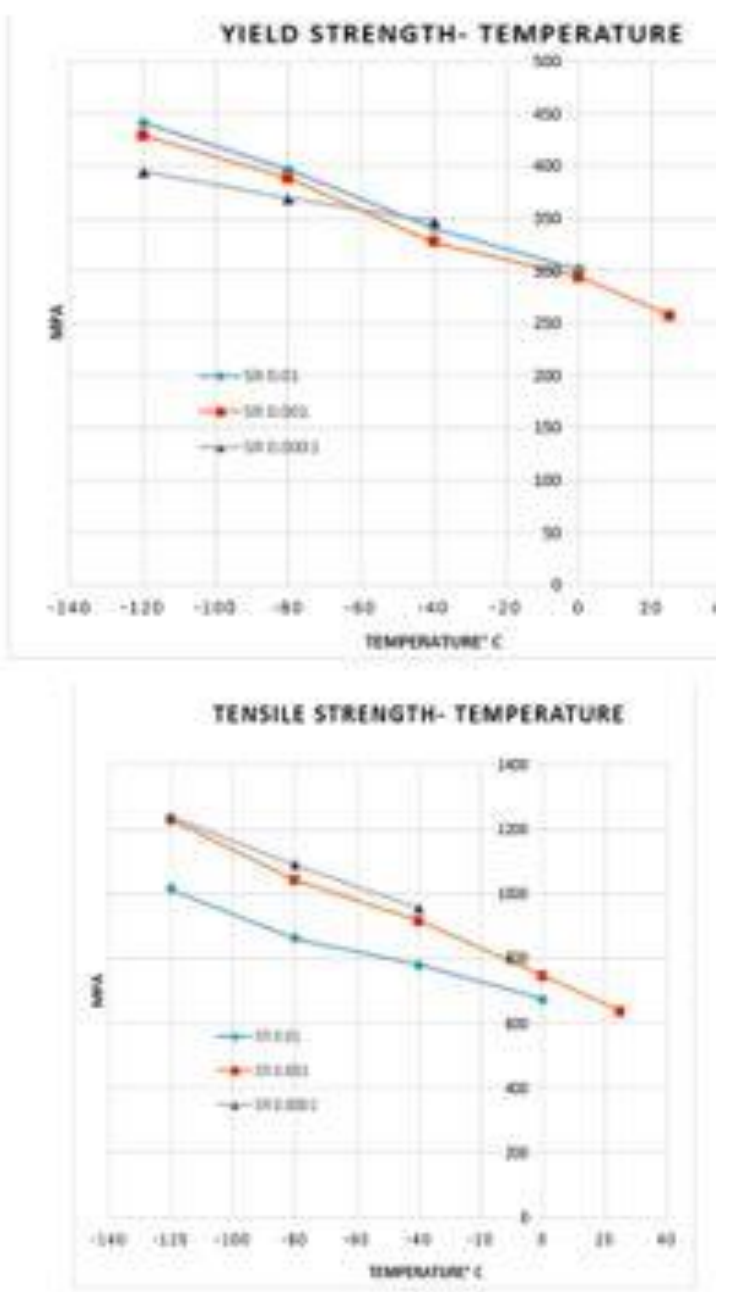

Figure 5 Yield strength and tensile strength comparisons as function of strain rate

The Optical Microstructure of as received sheet is as showed fully austenitic structure. The microstructure at $1000 \mathrm{X}$. is shown in figure 6

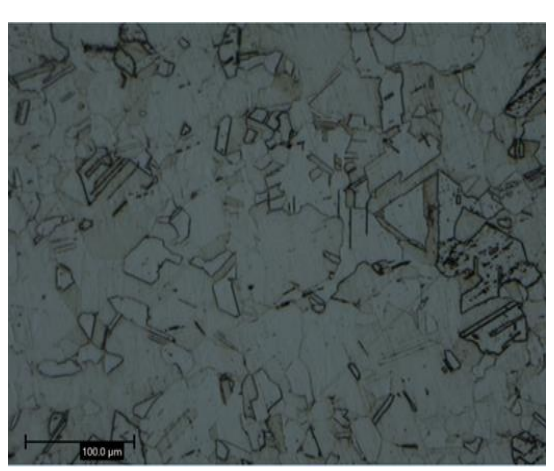


Figure 6 optical microstructure of as received sheet

XRD pattern of as received sheet showed peaks of single phase, which is $100 \%$ Austenite as shown in Figure 7

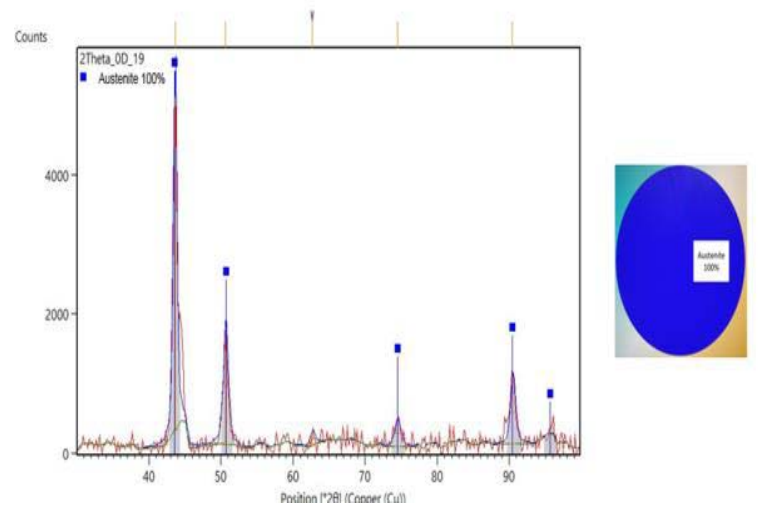

Figure 7 XRD pattern and phase fractions as received sheet

Phase fraction at each strain rate and temperature calculated by XRD characterization. It showed that increase of martencite percentage with decrease of temperature strain rate. Martencite percent was 0, at room temperature and 57 percent at $-120{ }^{\circ} \mathrm{C}$. The phase fraction at -80 and at a stain rate $0.001 / \mathrm{sec}$ showed 50\% Austenite and 50\% Martencite as shown in figure 8

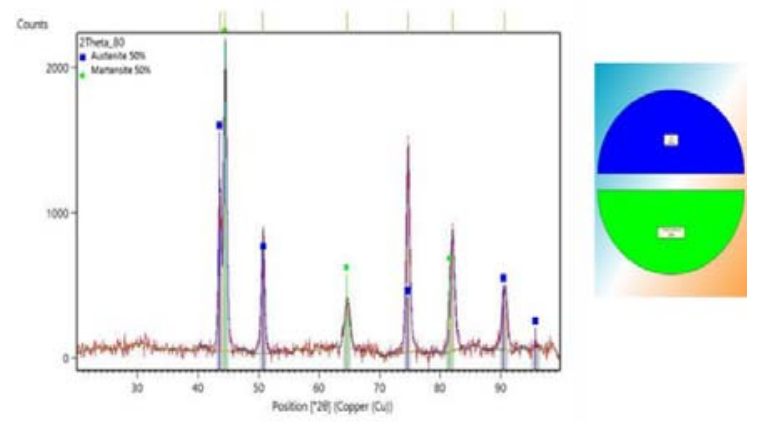

Figure 8 XRD pattern and phase fractions at $-80{ }^{\circ} \mathrm{C}$ and strain rate of $0.001 / \mathrm{sec}$

Grain average misorientation is calculated at each temperature and strain rate. It was found that it was increased with decrease of temperature and strain rate. Inverse pole figures, IPF at a strain rate of $0.001 / \mathrm{sec}$ at $80^{\circ} \mathrm{C}$ and $-120^{\circ} \mathrm{C}$ is shown in figure 9 and 10 . The Average grain size of Austenite in as received condition is $35 \mu \mathrm{m}$ (in undeformed condition).

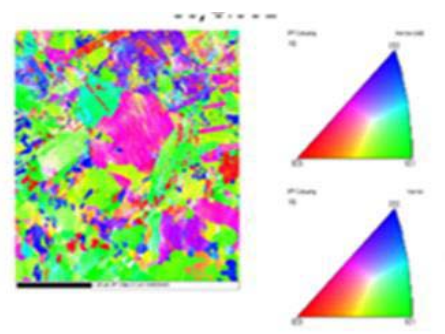

Figure 9 IPF for SR 0.001 at $-80{ }^{\circ} \mathrm{C}$

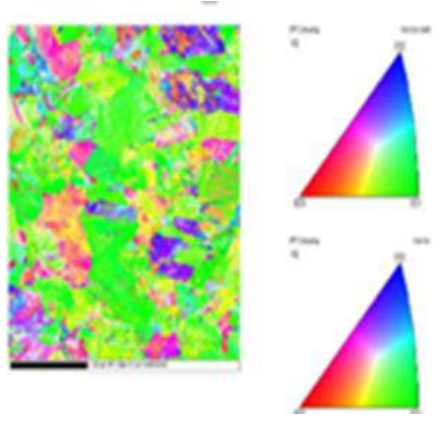

Figure $10 \mathrm{IPF}$ for SR 0.001 at $-120^{\circ} \mathrm{C}$

\section{Conclusions}

In this work, subzero temperature tensile behaviour of AISI 304 stainless steel was studied, then stress, strain plots were compared along with mechanical properties and phase fractions and microstructure. The following conclusions were drawn

i. Tensile strength is increased with the decrease of temperature, strain rate due increased percentage of strain induced martensite.

ii. Strain rate and temperature have strong effect on amount of martensite formation and corresponding mechanical properties.

iii. The increase in tensile strength is non uniform, due to secondary, tertiary hardening and strain aging etc.

iv. The change in Mechanical properties is significant at $-80^{\circ} \mathrm{C}$ compared to other temperatures.

v. The predominant deformation mechanism is Phase transformation, rather than slipping and twinning.

\section{References}


1. Baciu, F., Rusu-Casandra, A., Pastramă, Ş.D., 2020. Low strain rate testing of tensile properties of steel. Materials Today: Proceedings 32, 128-132.

2. Chen, G., Zhong, J., Zhang, X., Guan, K., Wang, Q., Shi, J., 2021. Estimation of tensile strengths of metals using spherical indentation test and database. International Journal of Pressure Vessels and Piping 189.

3. Cullity, B.D., Stock, S.R., Stock, S.R., 2001. Elements of X-ray Diffraction. Prentice Hall.

4. Desu, R.K., Nitin Krishnamurthy, H., Balu, A., Gupta, A.K., Singh, S.K., 2016. Mechanical properties of Austenitic Stainless Steel 304L and 316L at elevated temperatures. Journal of Materials Research and Technology 5, 13-20.

5. Koga, N., Nameki, T., Umezawa, O., Tschan, V., Weiss, K.-P., 2021. Tensile properties and deformation behavior of ferrite and austenite duplex stainless steel at cryogenic temperatures. Materials Science and Engineering: A 801.

6. Kori, P., Vadavadagi, B.H., Khatirkar, R.K., 2020. Hot deformation characteristics of ASS-304 austenitic stainless steel by tensile tests. Materials Today: Proceedings 28, 1895-1898.

7. Kweon, H.D., Kim, J.W., Song, O., Oh, D., 2021. Determination of true stress-strain curve of type 304 and 316 stainless steels using a typical tensile test and finite element analysis. Nuclear Engineering and Technology 53, 647-656.

8. Petit, B., Gey, N., Cherkaoui, M., Bolle, B., Humbert, M., 2007. Deformation behavior and microstructure/texture evolution of an annealed 304 AISI stainless steel sheet. Experimental and micromechanical modeling. International Journal of Plasticity 23, 323-341.

9. Quitzke, C., Schröder, C., Ullrich, C., Mandel, M., Krüger, L., Volkova, O., Wendler, M., 2021. Evaluation of straininduced martensite formation and mechanical properties in $\mathrm{N}$-alloyed austenitic stainless steels by in situ tensile tests. Materials Science and Engineering: A 808.

10. Raghavan, V., 2015. Physical Metallurgy: Principles And Practice, Third Edition. Phi Learning Private Limited.

11. Sahu, J., Chakrabarty, S., Raghavan, R., Mishra, S., 2018. Investigations of size effect on formability and microstructure evolution in SS304 thin foils. The Journal of Strain
Analysis for Engineering Design 53, 517528.

12. Zhang., R., Shao., Z., Shi., Z., Lin., J., 2020. A study on ratio and linearity of strain path in in-plane biaxial tensile test for formability evaluation. 18th International Conference Metal Forming 2020. 